Article

\title{
Performance Gap and Occupant Behavior in Building Retrofit: Focus on Dynamics of Change and Continuity in the Practice of Indoor Heating
}

\author{
Giuseppe Salvia ${ }^{1, *(\mathbb{D}}$, Eugenio Morello ${ }^{1, *(\mathbb{D}}$, Federica Rotondo ${ }^{1}$, Andrea Sangalli ${ }^{2}$, \\ Francesco Causone $^{2}$, Silvia Erba ${ }^{2} \mathbb{D}$ and Lorenzo Pagliano ${ }^{2}$ \\ 1 LabSimUrb, Department of Architecture and Urban Studies (DAStU), Politecnico di Milano, \\ 20133 Milano, Italy; federica.rotondo@mail.polimi.it \\ 2 End-use Efficiency Research Group, Energy Department (DENG), Politecnico di Milano, 20156 Milano, Italy; \\ andrea.sangalli@polimi.it (A.S.); francesco.causone@polimi.it (F.C.); silvia.erba@polimi.it (S.E.); \\ lorenzo.pagliano@polimi.it (L.P.) \\ * Correspondence: giuseppe.salvia@polimi.it (G.S.); eugenio.morello@polimi.it (E.M.)
}

Received: 18 March 2020; Accepted: 24 June 2020; Published: 20 July 2020

check for updates

\begin{abstract}
Building retrofit is often reported to fail in achieving predicted energy savings; this mismatch in post-retrofit conditions is labeled the 'energy performance gap' and may be due to both occupant behavior and technical issues. In this study, the occupant is investigated through a case study of a recently retrofitted public housing in Milan inhabited by 500+ tenants. Informed by social practice theory and interviews to households, concurrent and interdependent elements in heating space are identified-including factors of comfort, competences involved and other interconnected practices. Patterns of continuity and change in setting thermal conditions in this retrofitted building emerge. In this respect, key dynamics of the occupants are related to rooted habits in managing heating, social norms of thermal comfort, mastered skills in dealing with technical devices and infrastructure and ways of organizing other routines such as laundry and forms of entertainment when services are limitedly accessible. The results inform plans for energy efficiency through building retrofit in which the integration of the social dimension and practices may contribute to maximizing the impact of the intervention and to limiting energy performance gap.
\end{abstract}

Keywords: energy demand; energy use for heating; space heating; social practices; retrofit; case study; public housing; occupant behavior

\section{Introduction}

Building retrofit is an established strategy enabling a substantial reduction of energy use [1-3], most notably for space heating; it is pursued mostly by improving the quality of the building fabric through high performance thermal insulation or other techniques, and introducing high efficiency heat recovery on ventilation. Pushed by EU directives, plans have been developed by European countries for the renovation of the building stock $[4,5]$, especially including public and social housing [6-8]. These actions are expected to reduce final building energy use and constitute a major contribution for the reduction of greenhouse gases (GHGs), with buildings accounting for about a third of the global energy use, especially for space heating $[1,9]$. Among the building sector, the residential share dominates the use of energy for about a third of total figure in some European countries including Italy [10], Sweden [Swedish Energy Agency, cited by Palm and Reindl [11] ] and the UK [12].

The environmental burden of the building energy use is significant, with nearly $40 \%$ of carbon dioxide $\left(\mathrm{CO}_{2}\right)$ emissions worldwide [9]. Therefore, reducing the energy use in this sector, namely 
through building retrofit, is crucial to meet the European Commission's target of cutting GHG emissions down by at least $40 \%$ by 2030 and $80 \%$ by 2050 from their 1990 levels [13].

Nevertheless, retrofitted buildings are frequently reported to fail in achieving the predicted energy savings calculated to inform the design stage or for the purpose of energy performance certification [14-16]. The mismatch between the measured (or actual) post-retrofit energy performance of buildings and the predicted (or simulated) one is known as the 'energy performance gap'. In most studies, the energy performance is evaluated in terms of annual energy use of the whole building for heating (and cooling) purposes [16]. However, even if often presented as an evidence, energy performance gap needs to be clearly defined in order to be correctly evaluated and interpreted. Galvin [17] indeed reports miscommunication issues concerning the use of different metrics (e.g., energy performance gap, rebound effect, energy savings deficit) recurring in academic and policy literature, especially about thermal retrofits of existing homes.

The study reported in this paper provides evidence of the energy performance gap, which is an unintended consequence identified with respect to the post-retrofit stage [17]. This phenomenon is often labelled in literature as a version of the 'rebound effect' [18]. However, as explained by Galvin [17], "in broad terms, the 'rebound effect' quantifies the proportion by which the consumption of energy services increases as a result of an energy efficiency upgrade, and usually in relation to the proportionate increase in energy efficiency." Four items of information are required for this calculation, i.e., the actual and calculated consumption before and after the energy efficiency upgrade. For our case study no accurate information, based on measurements, is available about the pre-retrofit state; therefore, the rebound effect cannot be assessed. Neither the 'prebound effect' can be quantified, as it depends on pre-retrofit conditions [15] (Figure 1). In this paper, we elaborate on post-retrofit conditions and therefore we focus on the energy performance gap and its causes.

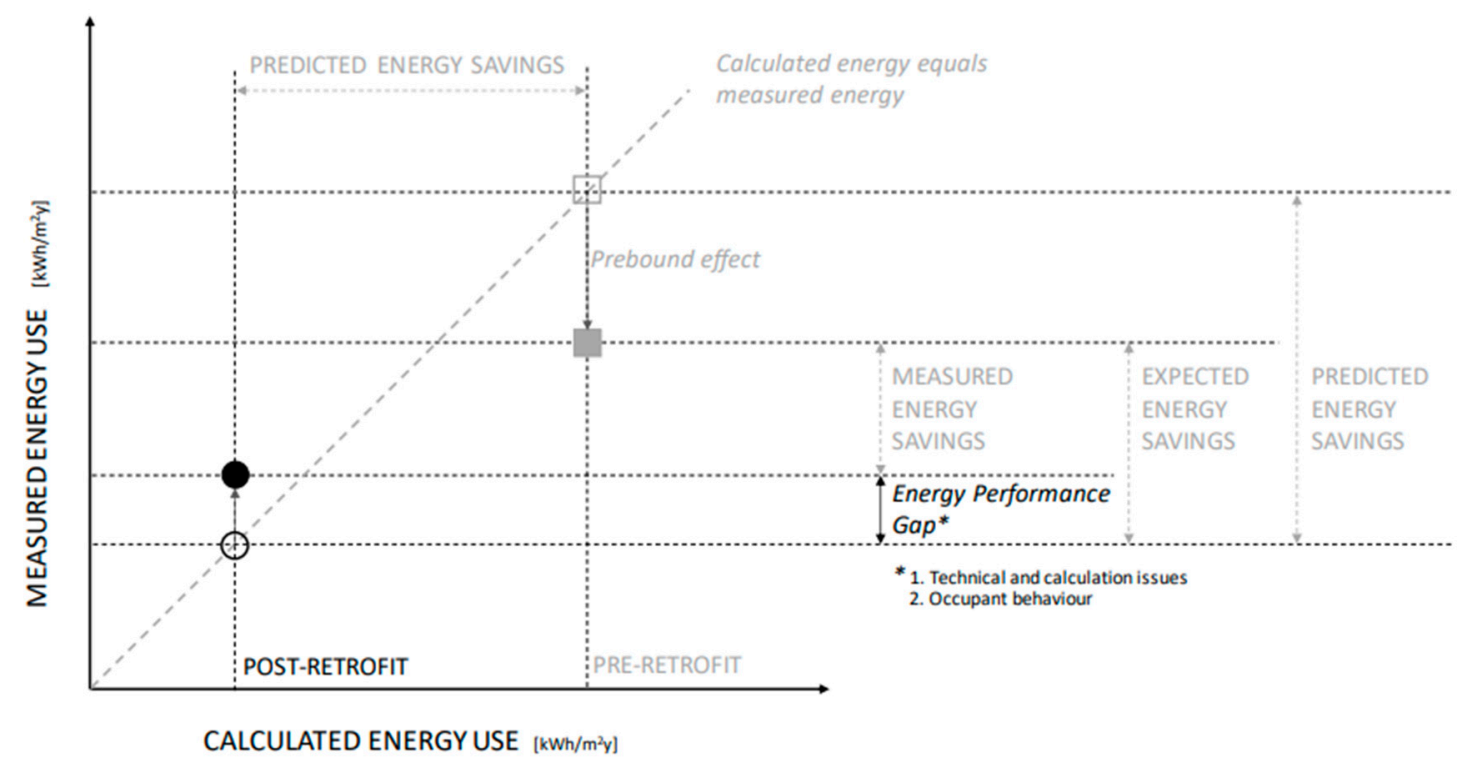

Figure 1. Conceptual representation of energy performance metrics in buildings comparing pre- and post-retrofit conditions. New elaboration of the graphic of Galvin [17]. The focus in this study is on the energy performance gap, which identifies a difference between calculated and measured energy use in the post-retrofit stage. The phenomenon is visually related to the centerline in the chart, along which calculated energy equals measured energy.

A literature review published in 2018 concludes that research has not reached the phase where the root causes of the phenomenon of energy performance gap could be effectively identified, managed and eliminated [19]. Uncertainties are present in both energy performance predictions and in energy performance measurements. According to some scholars [16,19], the causes of discrepancy between the expected and the measured energy savings can be categorized into three main groups, which correspond 
to the design, construction and operation stages of the building process. In the design stage, the main sources of uncertainties are the lack of appropriate assumptions (e.g., weather, construction thermal properties), the approximations present in every modelling method or tool, insufficient calibration of the created model [20] and the design concept (e.g., overestimation of systems' actual performance). Within the construction phase, a lack of correspondence between the design specification and the onsite construction quality may occur (due to, e.g., improper construction techniques, technical faults during installation, change orders, poor building quality) [21]. The operation stage is widely considered as a major contributor to building energy performance gap due to occupant behavior and a number of potential technical issues $[19,22]$. The combination of these two aspects is the basis of the EnerPop project informing this study, which focuses on occupants.

Occupant behaviors are recurrently indicated as a major source of the resulting gap [23-26], possibly because the dynamics of actual energy use and occupancy patterns are different from those assumed in energy efficiency norms or used as input in simulation tools [27-30]. Efforts are ongoing [31], trying to include in simulation tools a range of potential behavior patterns and associated probabilities rather than a single standardized pattern; nevertheless, those are mainly developed at academic stage, complex to use for mass design practice, and certainly not introduced into permit, documentation assessment and certification tools. Besides description in simulation tools, the issue of analyzing behavior and understanding ways that may help occupants to achieve comfort with minimal energy use is a relevant field of research with important practical implications.

Patel and Green [32] stress that energy performance assessment generally conceives buildings as static rather than dynamic, in continuous flow and transformation, with adaptations occurring throughout its lifespan, most notably deriving from the enactment of practice by the tenants. Diverse approaches are adopted for a better understanding of occupants' use of energy. Positivists, for instance, predominantly build upon quantitative based evidence and attitudes driving behaviors and choice [33,34]; these will possibly inform about factors to be considered in behavior modeling studies, including environment, time, context, physiology, psychology, society and others [35]. Similar approaches based on the identification of discrete elements to be accounted for the creation of a model in which factors and attitudes lead to behaviors and choices have been questioned [33], also for the limited results of behavioral change initiatives in energy use and environmental impact reduction [36,37].

The various approaches reflect the diverse types of gaps, which may be identified in the assessment of the effect of an intervention in buildings [38]. Nevertheless, a fundamental gap is identified in research domains addressing energy efficiency [39] and scholars have been encouraging a deeper understanding of energy use and building renovation from a social science perspective [11,40-42]. Within this domain, socio-technical studies define buildings and people as mutually constitutive and coevolving $[43,44]$, i.e., they shape and change each other. Thermal comfort is multidimensional and determined by diverse factors, namely sensory qualities, cultural roles and symbolism [45].

Studies based on social practice have been providing relevant insights regarding how occupants arrange the multiple elements available to them for achieving thermal comfort. In this effort of arranging, managing, juggling and adjusting, comfort results into a sociocultural achievement rather than a universally definable state of affairs, as typically framed in standards used in policy and engineering [46]. In other words, comfort is a goal, which people actively pursue in diverse ways, and may easily clash with predetermined references, which are intended to represent a general condition.

Building on social practice theory, this study intends to inform about social dynamics and more generally how occupants organize their activities, which affect the use of energy for space heating. The scope is limited to the winter season, during which more evident variations of energy use and practices are detected and energy performance gaps may occur. The insights generated shed more light on dynamics which occur in practice, although not necessarily captured in building retrofit plans and energy use models. These may be beneficial to consider in retrofit plans and intervention.

The investigation relies on semi-structured interviews with occupants of a recently retrofitted public housing in Milan and compares findings to energy measurements. The case study constitutes 
one of the multiple sites of the approximately 66 thousand public housing units present in the city. Between 2015 and 2017, the City Council invested approximately 50 million euros, i.e., about a third of the overall budget, for ordinary and extraordinary maintenance of public residential buildings, specifically to energy efficiency implementations. A better understanding of the way energy is used and may be optimized in the residential housing stock is crucial to maximize investments and energy performance, to minimize the environmental impact and to improve thermal comfort and air quality.

The key reflection deriving from the investigation is the importance of framing tenants' ways of living and dealing with climate indoor management. We frame heating and other interrelated practices carried out by the occupants as preceding the technical interventions of the building retrofit. As the technical intervention introduces novel elements into the environment and occupant' life, routinized dynamics are reproduced or adapted in the new retrofitted environment, in continuity or not with former ways of doing. More specifically, we hypothesize that keeping the house comfortably warm in winter in our case study (described in the section 'Materials and methods') is a process iterated over time and finally results into a highly routinized practice. In this view, the retrofit intervention occurs as an instance of potential change and disruption in the ways and times people were used to manage the indoor climate, through the devices, skills and other elements available to them. Nevertheless, tenants may not always react to change in the way that retrofit plan anticipates or expects for optimal energy use, thus leading to energy performance gaps. The results of the fieldwork-based study contribute to the identification of dynamics of continuity and change in occupants' routines emerged after the retrofit. The authors focus on three main instances of continuity and change on people's practices of energy and indoor climate management, presented in the results section and finally discussed:

1. What is produced as a comfortable indoor setting in relation to needs, expectations and social norms?

2. How are indoor thermal conditions and arrangements aligned and interrelated with other practices and routines (e.g., working times, cooking and bathing)?

3. How are the elements for thermal regulation (e.g., thermostat, radiator valves, windows and curtains) managed to achieve the aimed thermal comfort in relation to the competences mastered by the occupants?

Drawing on social practice theory, briefly presented in the following section, the insights of this study inform future research and projects regarding building retrofit. We infer and suggest that the retrofit is to be envisaged as a moment of change and disruption for occupants' routines, which requires a plan of intervention in order to limit chances of unintended consequences and gaps between predicted and actual energy use.

\section{Theoretical Framework: Social Practice Theory}

Theories of social practice are envisaged fruitful for shedding light to the above three research questions. As inferred by Rinkinen and Jalas [47], practice studies have started to see thermal comfort as a negotiated, non-standardized achievement, varying with the occupant [46,48]. Shove and Walker [49] clearly state that:

'understanding energy is first and foremost a matter of understanding the sets of practice that are enacted, reproduced and transformed in any one society, and of understanding how material arrangements, including forms of energy, constitute dimensions of practice.'

This suggests that in order to identify how energy is used, transformed or even wasted (in the case of energy inefficiency), human activities using, transforming and wasting energy have to be identified and understood, with particular attention to the devices and in general material elements involved in the provision of the service.

The core element of the multiple practice theories is the conception of 'practices as embodied, materially mediated arrays of human activity centrally organized around shared practical understanding' [50]. This definition stresses main elements of the interpretation of what people 
do, which include the central role of artefacts and technology in the reproduction of diverse actions occasionally interrelated between each other through bodily, physical experiences commonly known to or shared by wider society typically in a practical way. In this theory, the role of individuals is decentralized in favor of the practice considered as unit of analysis, 'attending less to individual choices and more to the collective development of modes of appropriate conduct in everyday life' [51].

Practices are 'temporally and spatially dispersed nexus of doing and sayings' [Schatzki 1996, cited by Shove and colleagues [52] ], so they exist independently from the specific moment and -notably for the objectives of this study - pre-exist to technical interventions, including building retrofit for energy savings.

A streamlined approach by Shove and colleagues [52] identifies three fundamental elements connected by people to perform a practice, i.e., materials (e.g., objects, technologies and in general tangible things), competences (i.e., skills, know-how and technique) and meanings (i.e., symbolic meanings, ideas and aspirations). In this view, the unit of analysis of the case study is the practice of maintaining indoor thermal comfort, rather than infrastructures, policies or even people. Technologies (e.g., thermal controlling devices) and the competences required namely for their setting may vary in the performance of the practice, across time and space, in order to meet the aspirations of each person, i.e., the 'carrier' of the practice [53]. Practices have to be performed continuously to persist and supersede [51,52], thus competing with other practices for time and attention.

This model helps to overcome the limits of some behavior-oriented approaches based on personal will or rational choice [54] in favor of the understanding that change in energy intensive practices-including keeping thermal comfort-requires effort in reconfiguring routinized, relatively established connections between the elements constituting the practice. In practice theories, 'engagement in the practice, rather than any personal decision about a course of conduct, [ ... ] explains the nature and process of consumption'. [51] As stressed by Shove [55], 'what matters is the relation between (more or less efficient) technologies, systems and appliances and co-evolution of routines, habits and practices.'

Also, competence plays a fundamental role for social practice theories, according to which knowledge and abilities are part of the practice rather than the practitioners, who make use of them 'situatedly', i.e., in a specific moment and context. Competences are distributed between the elements of practice [56], namely shared between the carrier of the practice, the devices for regulating heating and the wider group of people and technologies involved.

Furthermore, same elements may be arranged for multiple, interconnected practices, such as driving a car for shopping or going to work. Similarly, keeping indoor thermal comfort and heat management 'can form a lively nexus of interrelated practices through which practitioners become more or less involved in radiating warmth throughout their homes'. [47] As emerged in the case study presented, heating is interrelated likewise to cooking, laundering or even being entertained. Apartments result into material artefacts themselves, which are used for the accomplishment of the various activities of living and housing, including heating and staying warm.

Few scholars attempted to frame energy use for thermal comfort within social practice, namely to unpack the diverse use and domestication of technology for heating [57] and the effect of varied technologies in determining comfort [58]; the interplay of senses in determining comfort [59]; change in heating when moving into a new house [47]; the practice of ventilation [60,61]; smart metering feedback [62]; and even the practice of retrofitting [63,64] and the reasoning of professionals addressing energy efficiency [11].

In our study, we intend to further explore technologies, competences, continuity and change in practice as they seem to play a major role in setting and keeping thermally desired conditions. Notably, Gram-Hanssen [57] explores change and continuity in several household energy consumption practices; whereas she focuses on transfer of change brought about by elements (specifically technologies) from different practices they belong to, our key point of interest lies on continuity also with respect to former 
arrangements of domestic heating and the reconfiguration of the dynamics holding competences, materials and meanings in a novel environment.

\section{Materials and Methods}

\subsection{The Case Study}

The case study analyzed regards 154 households in a retrofitted public housing located in the periphery of Milan (Italy), where the actual energy use exceeds the expected (calculated) one at the design stage [65] and in particular in the legal calculations required for the construction permit. No accurate information, based on measurements, about the pre-retrofit state is available. The building has remained unoccupied for more than a decade due to the diffuse presence of asbestos, the process of removal and the subsequent retrofit; the documentation pre-retrofit is no longer available. Over 500 tenants live in apartments of two (the majority) to four rooms and distributed across two building blocks of four stories each (Figure 2). They are mainly represented by elderly Italian people (single or couple) and families of first-generation immigrants with children. Circa $30 \%$ of the inhabitants are under the age of 15 and $60 \%$ of the families are foreign, including more than 30 different nationalities.

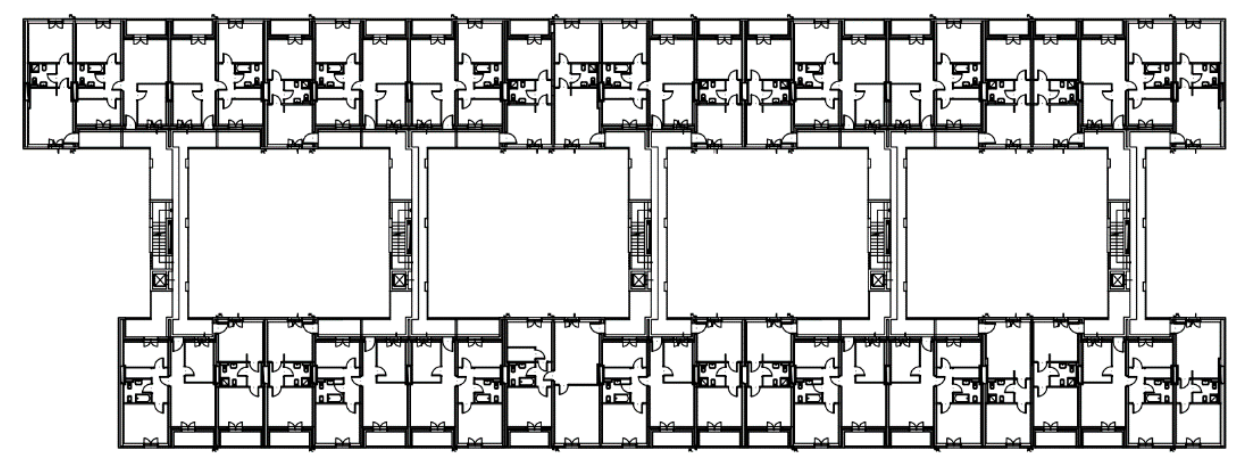

Figure 2. Plan of the building typical floor of the case study.

All the households accessed for the first time to the allocated apartment after 2014, when the main interventions of a major energy refurbishment, connected to asbestos removal and intended for thermal comfort and air quality improvement, were concluded. The retrofitting greatly improved the building envelope and the building energy systems through a multitude of interventions [66], which included - most relevantly for the objectives of this study - the installation of thick external insulation, lowering the average $U$-value of external walls and roof (respectively from 0.84 to $0.19 \mathrm{~W} /\left(\mathrm{m}^{2} \mathrm{~K}\right)$ and from 2.19 to $\left.0.33 \mathrm{~W} /\left(\mathrm{m}^{2} \mathrm{~K}\right)\right)$; replacement of existing windows with double-glazed ones ( $U$-value lowered from 3.75 to $1.42 \mathrm{~W} /\left(\mathrm{m}^{2} \mathrm{~K}\right)$ ); connection to district heating network; installation of a programmable thermostat in every apartment and standalone thermostatic valves on the radiators (for control purposes only, as billing is not based on individually metered consumption). A centralized mechanical ventilation system has also been installed, which operates in extraction only, with extraction vents placed in the bathrooms and fresh air entering the apartments through intake vents placed on the façade. The system works with constant flow and at low speed. Sensors were installed to assess the performance of the building, by monitoring thermal energy required to reach and maintain the value of air temperature set on the programmable thermostats in every apartment. The thermal energy meters, installed in each apartment on the heating manifold, consist of two temperature sensors (one on the supply circuit and one on the return circuit) and an ultrasonic volumetric flow meter (Table 1). Additional sensors for the monitoring of temperature, humidity and $\mathrm{CO}_{2}$ at hourly time step were installed in 17 apartments of households who voluntarily agreed to this monitoring (Table 1). 
Table 1. Technical characteristics of the sensors. (Source: SVM, Capetti).

\begin{tabular}{cccccc}
\hline \multicolumn{2}{c}{ Energy Meter: SVM F25 } & & \multicolumn{2}{c}{ Indoor Environment Sensor: WineCap WSD00TH5CO } \\
\hline Temperature sensor & $\mathrm{Pt} 500$ & & Temperature & Relative humidity & $\mathrm{CO}_{2}$ concentration \\
Volumetric flow sensor & $\mathrm{Class} 2$ & Sensor type & NTC $10 \mathrm{k} \Omega$ & Capacitive & Infrared \\
Interval of temperature & $15-130^{\circ} \mathrm{C}$ & Range & $-10{ }^{\circ} \mathrm{C}-60^{\circ} \mathrm{C}$ & $0 \%-100 \% \mathrm{RH}$ & $0-5000 \mathrm{ppm}$ \\
Resolution & $1 \mathrm{kWh}$ & Accuracy & $\pm 0.2{ }^{\circ} \mathrm{C}$ in the & $\pm 5 \%$ at $25{ }^{\circ} \mathrm{C}$ and & $< \pm 50 \mathrm{ppm} \mathrm{in} \mathrm{the}$ \\
& $0.01 \mathrm{~m}^{3}$ & & interval $0{ }^{\circ} \mathrm{C}-60^{\circ} \mathrm{C}$ & $50 \% \mathrm{RH}$ & interval $0-5000 \mathrm{ppm}$ \\
\hline
\end{tabular}

The monitoring activity reveals inconsistencies between the calculated energy use as per building performance certificate (equal to $35 \mathrm{kWh} / \mathrm{m}^{2} \mathrm{y}$ averaged over 154 apartments) and the actual use by households (equal to $63 \mathrm{kWh} / \mathrm{m}^{2}$ y averaged over 154 apartments) of the case study during the heating season [59] (Figure 3). Calculated as the ratio of the overconsumption of energy over the design energy use in the post-retrofit conditions $[17,18]$, the energy performance gap is equal to $80 \%$ in this case study. Indoor temperatures commonly exceed the $20 \pm 2{ }^{\circ} \mathrm{C}$ imposed by regulations. [67] This large difference in expected and actual indoor temperature may explain the significant gap in energy use, which results from the complex interplay of two main types of sources: technical issues linked to sizing and regulation of the heating supply on one side and occupant behavior on another side, the latter of which is the focus of this study. The deep retrofit works were supervised by an experienced technical team of the Municipality of Milan and validated by Politecnico di Milano in the framework of the EU-GUGLE project [68], therefore it seems unlikely that errors in the construction phase may represent a significant source of performance gap in this case.

In particular, at least two additional phenomena emerge from the observation of the monitored data, which suggest that energy use is related to complex dynamics:

1. The wide spectrum of indoor temperature across the apartments, especially with respect to the warmer season (Figure 4); this triggers a reflection about what thermal comfort is for occupants.

2. The lack of correspondence between variations of temperature and heating energy use, as warmer environments may require lower energy input and vice versa (Figure 3). This raises questions about the diverse ways this is achieved by occupants of the same building.

In the subsequent section, the results of the fieldwork activities intend to shed lights on these phenomena.

\subsection{The Interviews}

In this study, results are drawn predominantly from interviews to a sample of tenants, complemented with home-tours, whenever the tenants agreed. Interviews are widely used in social research [69] and, as inferred by Hitchings [70], they may provide relevant insights about mundane practices likewise, including handling cold in winter.

The flexible format of semi-structured interviews fit the purpose for the scoping nature of the project, the range of topics to be explored and the size of the project [69]. The interviews were accomplished with a fairly representative sample of householders, until saturation of themes and repetition of contents were achieved. In total, between May 2018 and May 2019, 15 tenants were interviewed, residing in 11 different apartments, six of which were selected among those living in the 17 apartments equipped with additional environmental sensors. The sampling aimed at maximizing representativeness with respect to apartment placement (floor, exposure) and, in particular, citizenship and composition of the family (single, couple, family with children). Several households declined the invitation to be interviewed, especially among families of foreign origin. In order to avoid the over-representation of domestic habits and practices by similar type of households that originally agreed to be interviewed (typically small families of Italian origin, without children), the sample was expanded to include families of foreign origin, although residing in apartments which were not equipped with the aforementioned environmental sensors. 


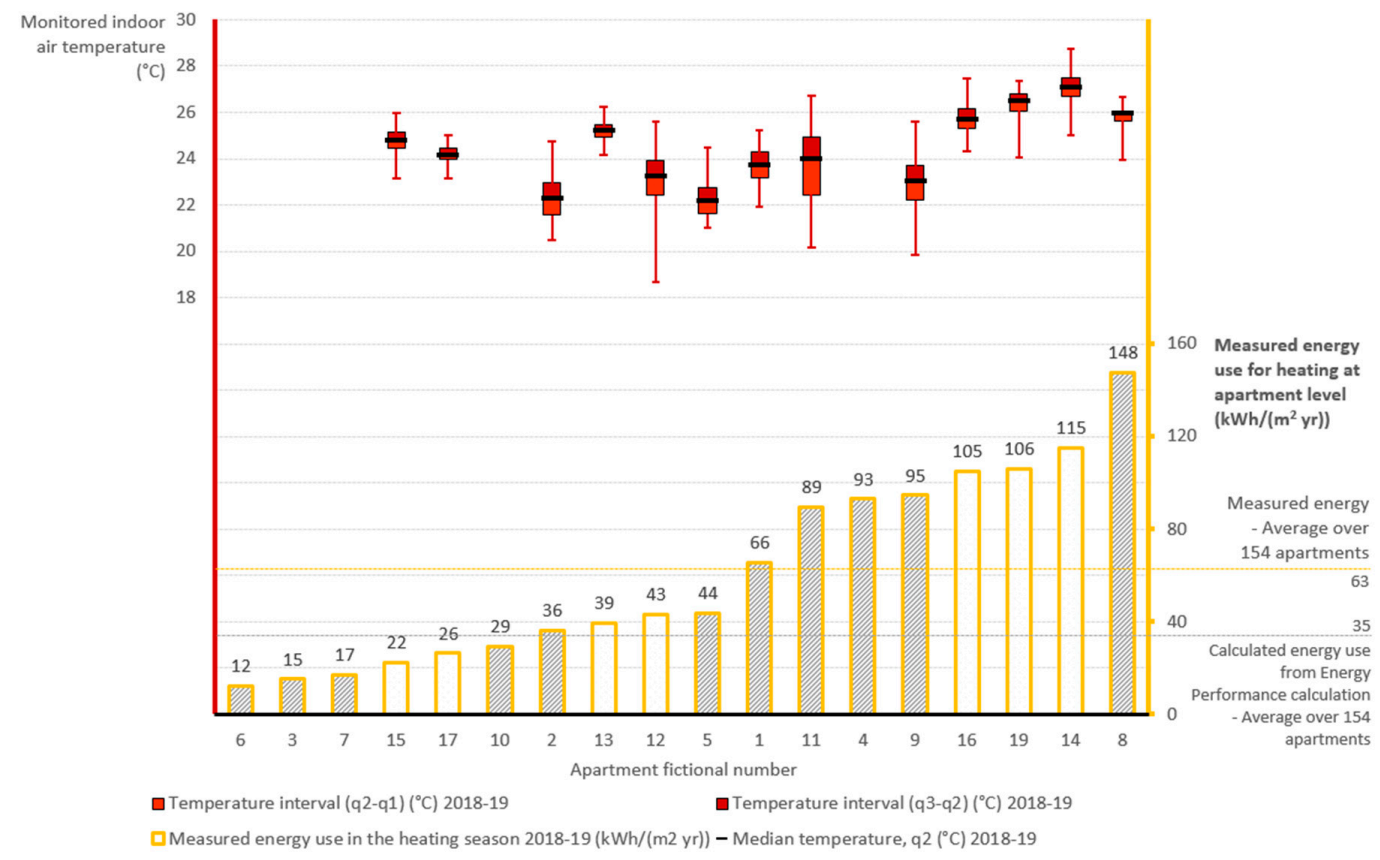

Figure 3. Measured energy use for heating in 18 apartments compared with both average measured energy use and calculated energy use for the whole building, during the heating season 2018-2019. The sample includes the data of the apartments of the interviewees and the apartments equipped with environmental sensors for which energy use data are available. Furthermore, shown, on the left axis, the monitored air temperature at the center of the apartment for the 18 apartments, during the same heating season. The apartments of the interviewees are indicated with crossed area. Three apartments of the interviewees' sample are not equipped with environmental sensors; hence temperature recordings are not available. Energy is measured at the entrance of each apartment, therefore thermal losses until this point are not accounted. The statistical distributions of the indoor air temperatures in the apartments are represented by a box-and-whisker graph. In this graph, the quartiles are indicated by red-tone bars (first quartile, q1, second quartile or median, q2 and third quartile, q3) and the maximum and minimum values, included, respectively in the interval [q3 + 1.5* (q3-q1)] and [q3-1.5* (q3-q1)], are represented as whiskers above and below the quartiles. For apartments on two levels, where two sensors were installed-one for each floor-the arithmetic average temperatures were calculated hour-by-hour and then the statistical analysis was performed.

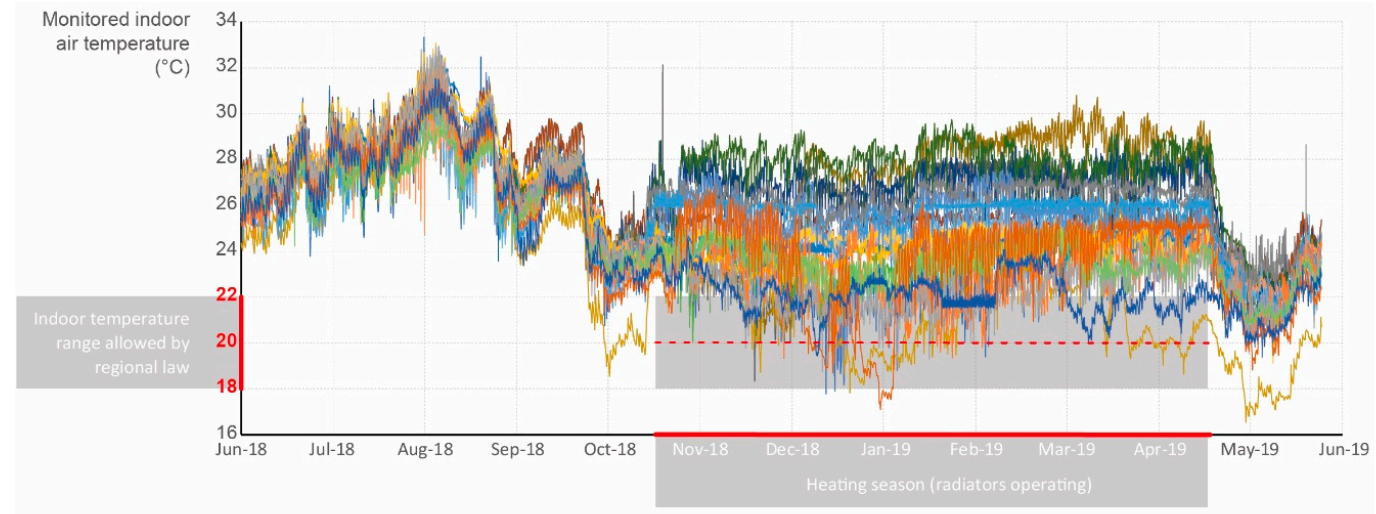

Figure 4. Temporal variation of indoor temperature. Temperature was monitored from June 2018 to May 2019 in 17 apartments equipped with environmental sensors in the building of the case study. The range of indoor temperature allowed by the national law [67] (i.e., $20 \pm 2{ }^{\circ} \mathrm{C}$ ) during the winter heating season (from 15 October until 15 April) is highlighted in the chart.

Table 2 summarizes the characteristics of the interviewees. 
Table 2. Summary of the interviewee main characteristics, in the order of the date of the interview. The origin of non-Italian interviewees is not specified to prevent identity disclosure. The members of each couple were interviewed in the same session.

\begin{tabular}{|c|c|c|c|c|c|c|c|}
\hline $\begin{array}{l}\text { Interviewee's } \\
\text { Pseudonym }\end{array}$ & Age & Gender & Citizenship & $\begin{array}{l}\text { Living with } \\
\text { Adult/s }\end{array}$ & $\begin{array}{l}\text { Living with } \\
\text { Child/Ren }\end{array}$ & $\begin{array}{l}\text { Apt. } \\
\text { Floor }\end{array}$ & $\begin{array}{c}\text { Interview } \\
\text { Date }\end{array}$ \\
\hline Alberto & 65 & M & Italian & No & No & 0 & 05/2018 \\
\hline Carlo & 84 & M & Italian & \multirow{2}{*}{ Yes } & \multirow{2}{*}{ No } & \multirow{2}{*}{1} & \multirow{2}{*}{ 05/2018 } \\
\hline Diana & 78 & F & Italian & & & & \\
\hline Francesco & 50 & $\mathrm{M}$ & Italian & \multirow{2}{*}{ Yes } & \multirow{2}{*}{ Yes } & \multirow{2}{*}{$3-4$} & \multirow{2}{*}{ 06/2018 } \\
\hline Giovanna & 49 & F & Italian & & & & \\
\hline Ignazio & 66 & $\mathrm{M}$ & Non-Italian & \multirow{2}{*}{ Yes } & \multirow{2}{*}{ No } & \multirow{2}{*}{0} & \multirow{2}{*}{ 06/2018 } \\
\hline Laura & 58 & F & Non-Italian & & & & \\
\hline Marianna & 71 & F & Italian & No & No & 0 & $07 / 2018$ \\
\hline Noemi & 31 & F & Non-Italian & No & Yes & $3-4$ & $10 / 2018$ \\
\hline Oriana & 48 & F & Non-Italian & Yes & Yes & 2 & $12 / 2018$ \\
\hline Paolo & 49 & $\mathrm{M}$ & Italian & \multirow{2}{*}{ Yes } & \multirow{2}{*}{ Yes } & \multirow{2}{*}{$3-4$} & \multirow{2}{*}{ 02/2019 } \\
\hline Rosa & 28 & F & Non-Italian & & & & \\
\hline Simona & 45 & F & Non-Italian & Yes & Yes & $3-4$ & 02/2019 \\
\hline Ugo & 45 & M & Non-Italian & Yes & Yes & 2 & 03/2019 \\
\hline Valerio & 67 & $\mathrm{M}$ & Italian & No & No & 1 & $05 / 2019$ \\
\hline
\end{tabular}

The available and selected candidates were asked to participate to an interview of approximately 60 to $90 \mathrm{~min}$ in their home, on a voluntary basis (without reimbursement) at the preferred date and time.

The semi-structured interviews covered five main strands of investigation, as follows:

1. Everyday routines (e.g., going to work or school, cooking and eating, doing the laundry, cleaning, having a bath or shower, getting entertained) and their interrelations in time and space (e.g., happening simultaneously or one after the other, indoor or outdoor area where these occur);

2. What is considered an optimal condition for thermal comfort at home both in winter (which is the focus of this study) and in summer (out of scope in this study), mostly regarding temperature, humidity and ventilation;

3. Actions undertaken for the management of thermal comfort at home (e.g., setting and adjusting the thermostat, radiator valves, windows and rollers, layers of clothing, having a warm meal or shower, going somewhere warmer) and the user experience with the potentially key regulating devices, specifically the thermostat and the radiator valves (e.g., user-friendliness, time and temperature, setting) for the tenants, if more than one is engaged with them;

4. Living in public housing and in the building of the case study, with particular interest to the experience of moving in the apartment and familiarizing with the infrastructures (e.g., training if any, user-friendliness, perceived quality), the retrofit intervention (esp. if known), building rules (esp. if aware of them and generally respected), social relations across tenants (e.g., reciprocal support, knowledge sharing, conflict), comparison with former experiences (esp. other buildings and areas where the interviewee lived);

5. Interviewee sociodemographic details (e.g., profession, country of origin, education), family composition and potential special needs (e.g., children, elders, ill members, pets), expenses and their implications on family economic stability (e.g., utility bills, rent).

The interviews were held in Italian, which represents the native or additional well-known language for the interviewees; quotes-translated into English by the authors-are included in this study for the benefits that they bring to research and to the credibility of the collected data [71].

The interviews were audio-recorded with the interviewees' consent (denied by two of them, not fully verbatim transcribed, except for quotes in this study), paired with researchers' notes and 
analyzed with the support of software NVivo [72]. The software facilitated the tracking of themes and patterns of spatial heating through the open coding of the transcripts, i.e., the identification of conceptual categories emerging from data analysis [69]. More specifically, the strands of the interviews above - the general description and the text within brackets - constitute the emerged generic and basic themes, respectively, which were eventually interpreted into super-ordinate themes [69] and presented in the results below.

\section{Results}

Three main social features of continuity and change in practices involved in staying warm at home fundamentally through space heating emerge from the interview analysis, i.e.,:

1. The setting of the indoor thermal conditions responds to preferences and needs, which eventually results in a differentiation of practices;

2. Space heating is synchronized and interlocked with other practices;

3. Artefacts including devices and infrastructures (i.e., 'material elements') play a fundamental role in the negotiation of practice and these are closely interrelated to and interdependent with the competence and dexterity mastered by the tenant.

Figure 5 summarizes practices and material elements emerged from the interviews about heating the household, mostly presented in the following sections.

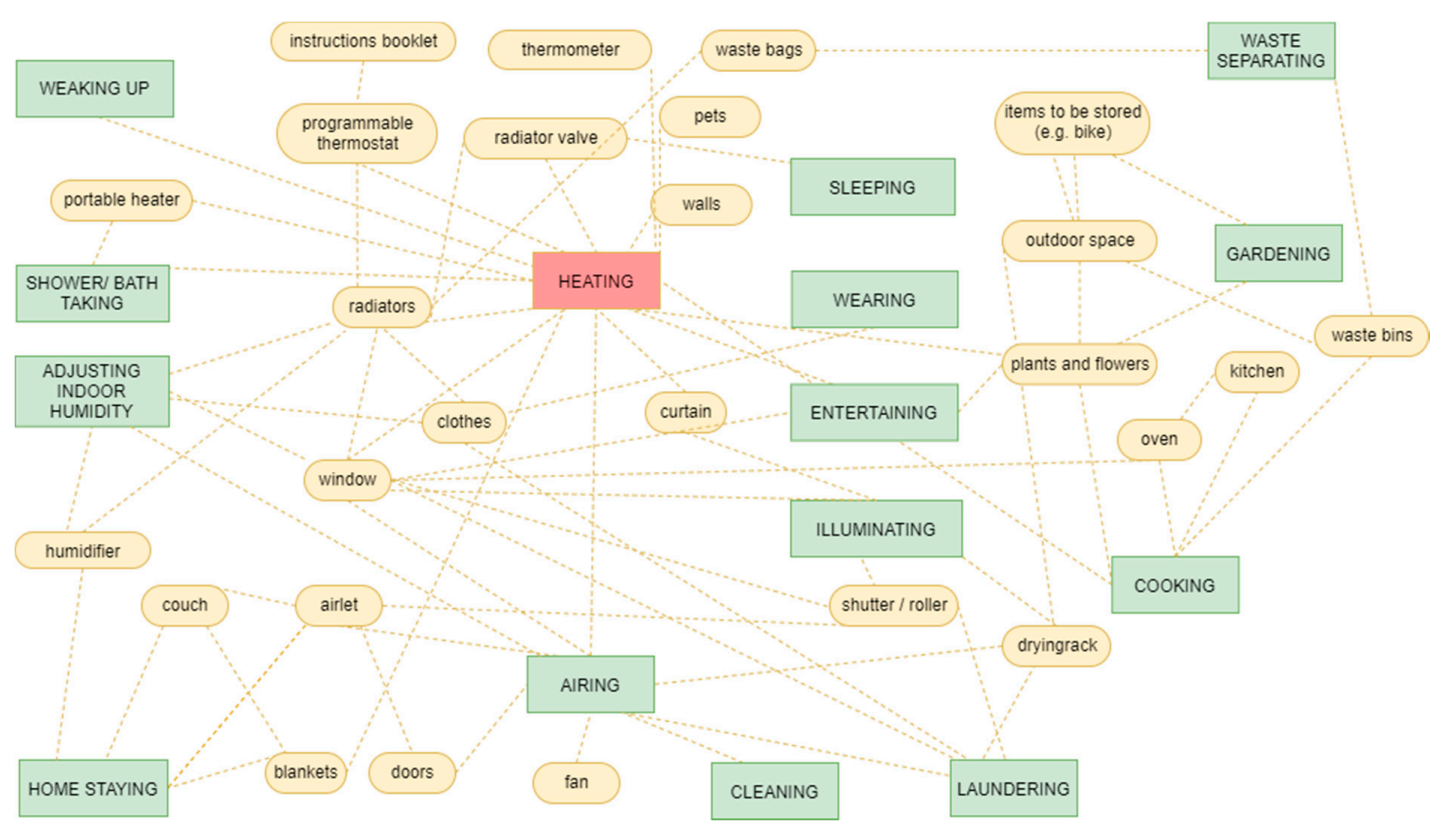

Figure 5. The web of practices in keeping thermal comfort at home. Visual representation of practices (squared boxes), involved material elements (rounded boxes) and reciprocal interconnections (dashed lines) emerged from the interviews addressing heating as the key practice.

\subsection{Setting and Preferences for Indoor Conditions}

Diverse preferences of thermal conditions are inferred from interviewees' words, which reflect the wider range of temperature monitored through indoor sensors (Figure 4). Carlo is wary of the maximum indoor temperature set by law and tends to stick to this. Marianna confessed that she tends to feel cold easily thus preferring warmer temperatures; in fact, she wears light pullovers even in summer mornings. On the other hand, tenants originating from warmer climate countries, like Simona and her husband, reported that they prefer to wear T-shirts even in winter most of the time, as they feel hot at home. Ugo and his wife feel likewise, sharing the same origin country of Simona's family. Ignazio states that his wife and he easily adapted to the Italian climate and more broadly to the 
cultural environment, because of the similarity of habits with the Southern American country of origin. Similarly, Alberto confesses that he is 'half-Greek' and he is used to warm conditions.

Independently from individual preferences towards warmer or cooler indoor temperature, interviewees tend to share satisfaction towards the structural building quality in maintaining the indoor desired warm environment in winter-although with chances of overheating in summer; radiators are inactivated in some rooms, most notably the kitchen (Francesco and Giovanna, Oriana, Simona) and small bedrooms (Oriana).

Additional heating devices are considered unnecessary by the interviewees, with only two households recurring to a small electric heater occasionally, especially early in the morning or in the case of general heating system malfunctions (Ignazio and Laura, Marianna). The excellent insulating infrastructural feature is particularly appreciated by two of the families interviewed, who had formerly lived in under-heated public housing. For Francesco and Giovanna, this former circumstance was detrimental to their child's health, which had improved remarkably since their relocation in the current housing.

Francesco "We applied for being relocated in a different [public housing] accommodation because we were in an inconvenient condition, because our son became asthmatic. He suffered cold as we had 11 ${ }^{\circ} \mathrm{C}$ [at home] in winter."

Giovanna "He had bronchopneumonia three times [ ... ] The important thing now is that it is hot indoor because I do not wish anyone to spend winter time at home wearing a coat and sleeping with four socks on."

A warmer environment is generally reported to be preferred in cases of vulnerability, including ill or in poor health tenants (Francesco and Giovanna, Marianna), younger family members and babies (Paolo and Rosa, Noemi, and Oriana); except for Simona's husband who suffers from hot temperature especially in summer time allegedly due to his diabetic condition.

Paolo "[t]he arrival of the [second] baby has changed the warmth at home dramatically. I imagine this is obvious. [ ... ] It does not make sense to keep the radiator on when you do your housework, when cooking, when you live your house. It makes sense when you have a really small girl at home."

Thermal conditions appeared actively negotiated also with grown up children (e.g., Oriana, Simona) as well as frequent visitors and between partners (e.g., Carlo and Diana, Paolo and Rosa, Ignazio and Laura), reportedly in favor of the represented female member. For instance, in summer time Oriana negotiates the occurrences when windows may be opened with the older daughter during her visits.

The presence of pets and other nonhumans may demand considerable amount of energy [73]. Alberto confessed to adjust temperature also in favor of the tropical fish and flowers hosted at home. Nevertheless, the householders who own or had owned a dog since they moved in the current apartment (i.e., Carlo and Diana, Paolo and Rosa) declared that their pet tend(ed) to appear comfortable at the temperature set for themselves or that the dog had to adapt to the set temperature.

Furthermore, airing is a common practice for the interviewees for more comfortable indoor conditions, typically synchronized with house cleaning and keeping, as reported in the subsequent section.

\subsection{Synchronizing and Interlocking Heating with Other Practices and Circumstances}

The practice of setting and adjusting indoor thermal conditions is related or dependent on other practices for they imply the presence (or absence) of the tenants or require temperature variations.

Most notably, radiators working times are recurrently said to be programmed according to school and working-hours. Namely, the heating system is programmed to turn on before getting up in the morning and to turn off when out for work or during holiday. 
Paolo "[Before the arrival of the second baby] we were more concerned about the other daughter, to let her find a warm house when back [from school] in winter. I was used to switch the radiators on in the morning for not letting her wake up in a really cold house and immediately after we switched them off."

Nevertheless, meticulous temperature adjustments are not common across the whole interviewees' sample; namely, a higher indoor temperature is occasionally monitored by the environmental sensors even when householders are absent.

Variations of indoor temperature appear related to and even intertwined with practices of house cleaning and airing, laundering, cooking and taking a shower, as briefly reported below.

The heat generated while cooking seems to affect summer time routines predominantly. For instance, Simona keeps the window constantly open in the kitchen, in order to let both heat and smells to effuse. She prefers fresh, cold food to avoid overheating from cooking. Similarly, Laura narrates she cooks at 4 a.m. for avoiding daytime hot temperature. Likewise, in winter some tenants keep the radiator in the kitchen at a lower temperature or even switched off (e.g., Simona, Francesco and Giovanna), possibly for the thermally insulated property of the walls.

Conversely, radiators in the bathroom tend to be maintained operative. Noemi increases the temperature of radiators particularly during her daughters' baths, whereas Paolo considers unworthy heating the bathroom after waking up early in the morning because of the limited time spent in washing himself before leaving home for work.

Indoor higher temperature results convenient also for laundering. Wet clothes may be placed outdoor on balconies or patios to dry (Laura, Giovanna and Francesco, Simona, Ugo, Virginia). Nevertheless, outdoor space is not always available for personal use, namely because the balcony is packed with other items or absent in some apartments (Carlo and Diana, Oriana); therefore, although forbidden by building rules, some tenants place laundry to dry on communal areas, including walkways and courtyards. In similar cases, the clothes obstruct passages and activities for others and tensions and conflicts between tenants arise (Carlo and Diana, Francesco and Giovanna, Rosa).

Additionally, in winter, wet washed clothes hardly dry outdoors (Ugo, Virginia), therefore drying laundry indoor appears the remaining solution, namely by using a tumble dryer (Paolo and Rosa) or the indoor heating. Diana places the wet clothes to dry overnight in the entrance, in the living room; likewise does Oriana, for whom a rapid drying of wet clothes is relevant to avoid indoor humidity excess and she places wet panty hose on the radiators. According to interviewees' anecdotes (e.g., Carlo), some other tenants increase the heating temperature considerably or leave the windows open on purpose for drying the laundry.

Oriana "In the evening I hang the wet clothes here [in the living room] as there is not room for hanging out, I roll down the shutter, but keep the window a bit open so that humidity does not accumulate [indoor] otherwise afterwards there will be smell of dump, that I do not like."

Almost all the interviewees report to occasionally or frequently open the windows for fresh air flowing into the apartment, especially in the bedroom in the morning. Valerio keeps the windows open every morning; he struggles to understand how some other tenants keep their windows closed and shutters rolled down.

Oriana "I have the windows always open [laughing] [ ... ] As soon as I get up, I like breathing a bit of air, even if it is contaminated, I do not care, I open the window."

Some tenants air the apartment for reducing the indoor humidity deriving from wet laundry hang to dry (e.g., Oriana). Interviewees report other tenants' practices of airing abundantly after cleaning the house, specifically after mopping the floors.

Although through personal experience rather than formal communications, tenants are generally aware of the mechanical ventilation system installed in their apartment, as they feel a breeze flowing through narrow vents mounted in the walls. 
Some interviewees (e.g., Valerio, Oriana, Marianna) prefer shutters rolled up for natural sunlight—-beyond fresh air-although they are aware that rolled down shutters limit heating dispersion substantially and preserve indoor temperature both in winter and summer time. Marianna stated that she usually keeps shutters and windows closed. However, since she had an accident obliging her to spend most of the time at home, "I suffer from claustrophobia, feeling closed and then I am obliged to open [the shutters]." The preference for rolled up shutters may relate to the relatively small size of the accommodation and the room were the interviewees live, in order to expand the perceived boundaries of the surrounding environment. Saving on artificial indoor lighting is an additional incentive for keeping shutters rolled up according to Valerio.

Various reasons may induce tenants to spend considerable time at home, including spare one. Rosa laments lack of benches in communal areas, where tenants may sit down and supervise their children playing outdoor yet within the building premises; therefore, some parents prefer their children to stay indoors, where supervisory roles may be enacted more effectively.

Some interviewees are affected by physical restrictions in their mobility due to age or disabilities. These conditions are described as restrictive also with regard to entertaining out of home, because of the limited public transport available in the surroundings. This is the case of Marianna, forced at home after an accident and hosting card game sessions daily with other tenants at home.

Few other interviewees complained the lack of services and opportunities of entertainment interesting to them in the local area, especially for shopping; this is particularly evident for those who formerly lived in a different, more lively urban area (e.g., Marianna, Simona, Oriana).

\subsection{Thermoregulating Devices: Competences, Familiarity and Preferences}

Multiple means are available to tenants for setting thermally favorite indoor climate, including thermostat, radiator valves, windows, curtains and clothes, which are described below. The interviewees interact with these means in a variable fashion in continuity not only with former habits and ways of doing, but also familiarity with them, dexterity or competences required.

A crucial product for the management of the indoor temperature is the programmable thermostat, installed in every apartment. Most the householders interviewed had their programmable thermostat set, generally according to their routines and needs. Some of them programmed - and when necessary adjust-this device by themselves, more precisely the male representative of the couple does it (Carlo and Diana, Paolo and Rosa, Ignazio and Laura, Francesco and Giovanna). Negotiations of indoor thermal conditions are affected likewise by the capability of each family member to effectively interact with the temperature regulating devices. For most the households interviewed, in which more than one occupant lives, the older male member (typically the husband or father) is the main responsible for setting and regulating the temperature; the female adult tenant usually describes herself less familiar or capable with the device, as she may fear to damage the system (e.g., Paolo and Rosa, Noemi, Simona, Oriana, Ignazio and Laura). For instance, for Carlo and Diana the asymmetric distribution of competence in managing the programmable thermostat and therefore the indoor temperature through this device in favor of the husband represents the occasion for some tensions between the two. Diana confessed that occasionally she attempts to increase the temperature beyond the limits set by the law which Carlo prefers to observe; he replies by letting her raise the indoor temperature until the radiators feel hot and eventually restoring the former temperature, allowed by the law.

Other tenants disregard this device because it is considered hardly comprehensible, at least without dedicating considerable attention. The interface of the programmable thermostat is described as confusing or counterintuitive also by some tenants, who are familiar with the device. For instance, icons of a sun, moon and ice flake indicate, respectively comfort (24/7 active), energy-saving and non-icing temperature-rather than daytime, night-time and cooling as some may interpret (Figure 6). 

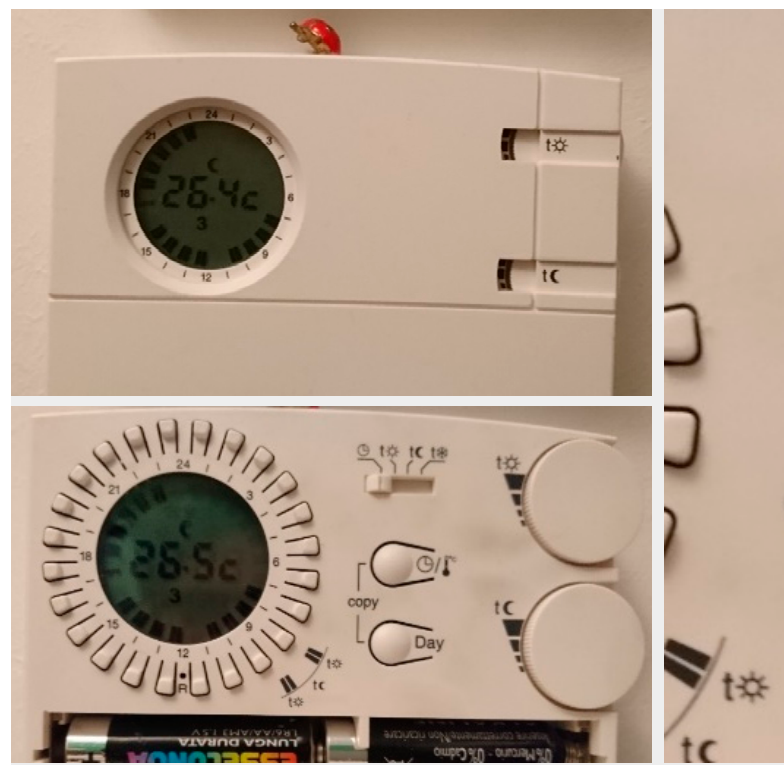
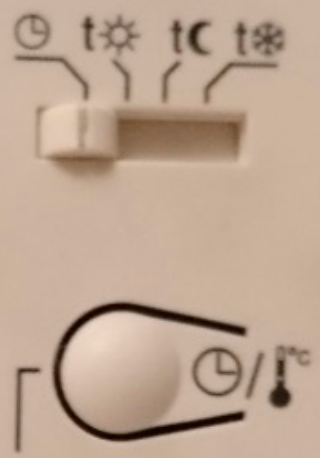

copy

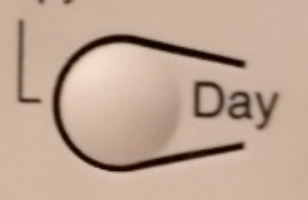

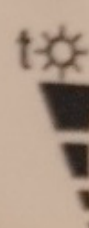

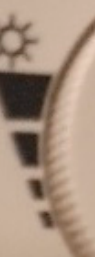

Figure 6. The programmable thermostat installed in the apartments of the case study (top left), as it appears when the lid is removed to enable its programming (bottom left), with a zoom-in on the icons used to indicate the multiple options available (right).

Some tenants experienced technical failures; in particular, the radiators performed differently from the setting imputed in the thermostat or they were inactive although the device was properly programmed-as witnessed by the researchers. Inconsistent actions and feedback from the thermostat had generated frustrations and major disruptions in daily life, including the inactivity of the heating system in the apartment.

Equally the instructions booklet is limitedly comprehensible for some, due to non-accessible technical jargon and undesired detailed descriptions. Some tenants ask for support to more expert ones. A couple of other households had the programmable thermostat set with the help of other tenants, yet they tend to struggle with occasional adjustments (e.g., Alberto). Simona leaves the management of the programmable thermostat to her husband for the fear of breaking this device, although she is the occupant spending more time at home. Similarly, Oriana asks to her partner (living in another building) for support not only because she is afraid of breaking the device, but also because she disregards product instructions. Carlo is reported by other interviewees to be highly supportive in programming their device; he highlighted crucial passages in his instructions booklet to communicate the setting procedures more effectively to the tenants asking for help.

Paolo declared to have successfully set the programmable thermostat by himself because of his former working experiences in the construction sector and the familiarity with other devices in this realm, similarly to other interviewees' experience.

Ugo quitted the use of the programmable thermostat because of the inconsistences between the actual temperature around the whole apartment and the one set on the device, which is placed by default in the central area of the apartment, usually in the corridor. To compensate and obtain a pleasant temperature throughout the lived areas, Ugo was used to set a temperature exceeding the law, until he suspected increases of energy bills resulting from this custom.

Some interviewees prefer to regulate thermal conditions by adjusting the thermostatic valve applied on each radiator, one per room, according to temperature variations during the day (especially Marianna, Laura). This device is particularly intuitive to use, with an integrated scale from 1 to 5 to set minimum and maximum radiated heat, respectively. Nevertheless, broken radiator valves are reported by one of the interviewees and with respect also to other tenants' experiences, possibly because of the intensive use deriving from continuously adjusting the device throughout the day. In an apartment visited by the researchers (not included in the sampling), valves were chewed by the dog and the 
radiator operated with the heat power as per last setting of the valve, before breakage. The high cost of a new valve prompted the tenants with a broken radiator valve encountered by the researchers to postpone or avoid replacement, with associated issues of missing or constantly operative radiator.

Excess of heat then is easily managed by opening the window. Interviews, anecdotes and observations confirm the common practice for few households of keeping the windows open while the heating system is operating, most notably for airing (see section above) or cooling the indoor environment in a timely fashion (e.g., Paolo, Noemi, Simona, Oriana).

Fabric is used for insulation by some, which explicitly refer to additional layers of clothing when feeling cold-rather than increasing the indoor temperature (e.g., Paolo and Rosa, Marianna). Paolo and Rosa suspended a curtain at the bottom of the staircase leading to the superior floor of their duplex (where bedrooms are located), in order to minimize conditioned air exchange between the two floors, both in winter with heat and in summer with cold air flows generated by the split air conditioner.

Finally, the external wall insulation system is invisible to tenants although the fundamental role played in limiting heat loss. Some interviewees are aware from former experiences or interest in constructions that walls are insulated (e.g., Paolo, Ignazio, Carlo). Nevertheless, general misinformation on the properties of the thermal coating and its mechanical resistance are reported, namely the type of suitable screws. Damages are observed from improper use, especially due to children playing at throwing a ball against external walls, with detrimental effects on the insulating layer.

\section{Discussion}

The results gained through the application of social practice theory in the case study sustain the understanding that "viewed as a dynamic enterprise, the achievement of comfort is [ ... ] a creative process of trading, juggling and manipulation whether of clothes, activity, and daily routine, or of building technologies" [48].

The efforts spent in such a creative process seem directed to ensure continuity to established arrangements. Nevertheless, the diverse elements and practices engaged in the process create opportunities for variations.

The analysis of the results highlights the following main characteristics of the indoor heating social practice in the case study:

1. The achievement of thermal comfort underpins dynamics of continuity and disruption in practice, especially with respect to cultural norms, formerly rooted habits and expectations;

2. Multiple practices are interconnected and interdependent with achieving thermal comfort and the deriving energy demand;

3. Preferences of comfortable conditions are achieved by managing devices and other elements available, which are closely interrelated and interdependent with competence.

These inferences are discussed below.

\subsection{Continuity with Norms, Rules, Shared Understandings and Bodily Preferences}

The ways through which interviewees manage heating are varied, consistently with the monitored environmental temperature (Figure 4) and literature [47,48,74] and with the ways in which practices are performed [51]. In this case study, variations of preferred thermal conditions occur within the same household likewise. For instance, consistently with some literature [75], thermal preferences may vary with age, with oldest interviewees reporting to feel cold more frequently. Personal comfort and environmental setting are negotiated in favor of vulnerable people, including younger family members' also in [76] for their special needs and routines [77]. A comparative analysis of hot water use for heating the apartments occupied by potentially vulnerable people (i.e., older and younger tenants) sheds more lights on this (Figure 7). Older tenants in this case study tend to demand higher energy with respect to the average household [78]. Conversely, ensuring a warm environment to children seems a non-sufficient condition for increased energy demand; a slightly lower use of energy 
is monitored with respect to the average household in the building. Possibly, an excessively high temperature is considered unfavorable for babies' health. Paolo and Rosa recurred to a humidifier for mitigating the air dryness at home caused by the heating system.

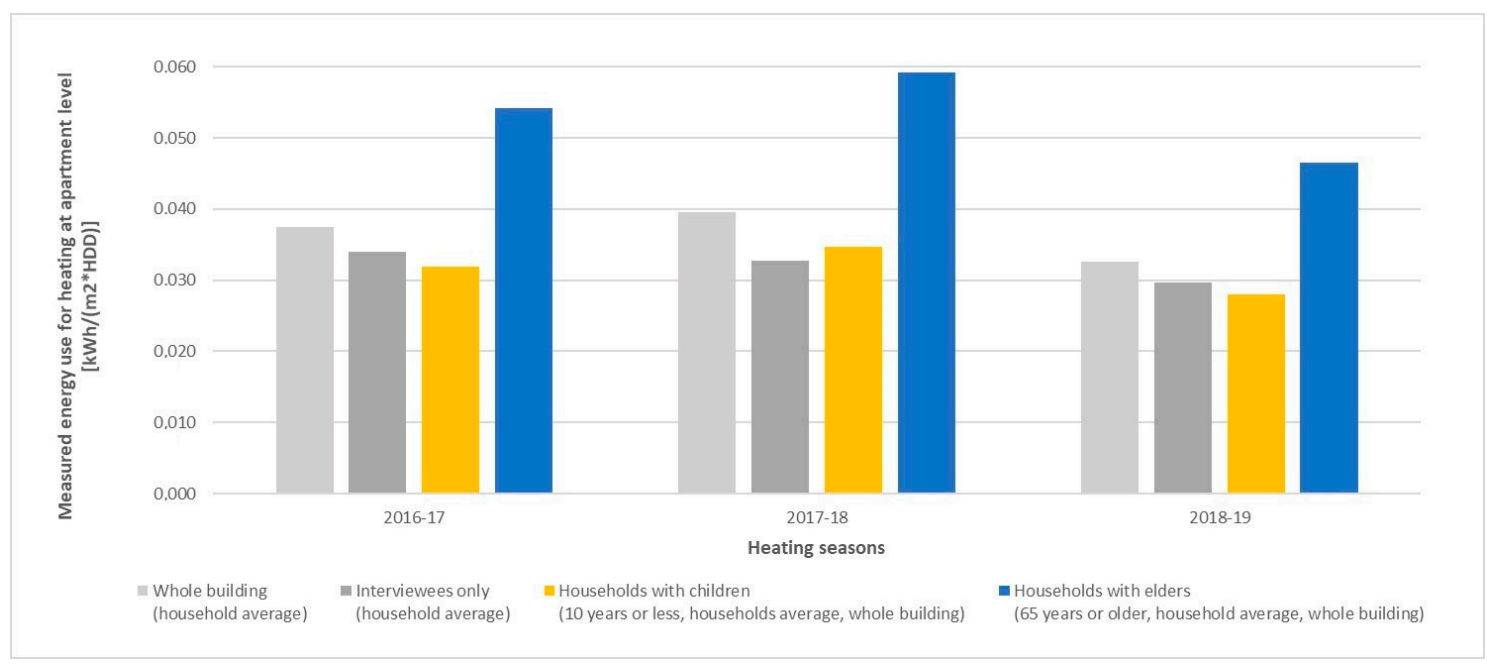

Figure 7. Energy use for space heating in the case study over three heating seasons, normalized to the heating degree days of each season. Data represent the average energy use per $\mathrm{m}^{2}$ of apartment for (i) the whole building (154 households); (ii) the apartments inhabited by the interviewees (11 households); (iii) the apartments inhabited by at least a tenant of 10 or younger (41 households) and (iv) the apartments inhabited by at least a tenant of 65 or older ( 26 households).

Social differentiation of practice occurs [51] with groups of people performing a practice differently. In our case study, substantial variations of heating practices emerge within a relatively small and recently established community, plausibly because of the considerable range of age, type of household, cultural background, nationality.

Although variable, an element recurs among them, i.e., the thermal indoor conditions are managed to achieve what is considered to be normal. The norms which interviewees seem to abide by include rules and instructions provided by governmental institution (e.g., the regional law on maximum temperature indoor), culture-rooted habits (e.g., wearing light clothes namely for some people originating from warmer countries or keeping the windows open for airing), shared understandings of comfortable or healthy environment especially for vulnerable occupants (e.g., children, ill or old people) or pets and shared meaning associated with ways of doing (e.g., using additional blankets to avoid the despicable waste of heat).

Therefore, shared cultural norms of ideal indoor conditions often diverge from normative standards, protocols and regulations, which are not necessarily known by the interviewees.

Information provision is encouraged for energy use reduction by some scholars [79] and government institution [4]. Nevertheless, the interviewees seem to be aware and knowledgeable on some key points of their energy use patterns and bills; therefore, we infer that information and knowledge may be already available to occupants, to some extent. Although relevant and possibly useful for some, information and feedback provision strategies may generate a limited impact towards the optimization of the use of the infrastructure and related energy use. As also implied by Gram-Hanssen [57], routines may more likely change via encounters, with other tenants showing 'new' norms, rather than mere provision of information by some external authority.

\subsection{Continuity, Synchronization and Interconnections with Other Practices}

Thermal regulation results interconnected and negotiated with diverse practices $[48,80]$, for the house itself representing a system of interlocked practices [81,82]. 
Indoor thermal conditions are set in relation to the goals and effects of other interviewees' routines, with particular reference to airing, drying the wet laundry and being entertained.

The interviews reveal how airing the house is a practice contributing to generating comfortable environment for the occupants, consistently with other studies $[59,83]$, namely for a pleasant smell or pursuing a connection with the outdoor environment.

Most notably, tenants recurrently hang wet clothes to dry indoor for unavailability of outdoor space or for reducing the time required. The need for fresh air, also related to the humidity generated by indoor laundering, is generally achieved by opening the windows, thus dispersing heat. Installed to minimize window opening and risks of molding, the forced ventilation system is centrally programmed to replace the entire apartment air volume every two to three hours. Nevertheless, manually airing by opening the windows is extensively practiced, thus dispersing the indoor heat. It may be inferred that preserving indoor heat has to be negotiated likewise with the need of fresh air and the common habit of airing by opening the windows, which may derive also from long time established routines and cultural norms [84].

Entertainment at home is common for tenants with limited mobility (e.g., hosting card game sessions). Furthermore, opportunities for outdoor activities, practical tasks (e.g., shopping) and divertissement are reportedly limited to this community, especially in the surrounding area. Some tenants seem keen to stay at home for longer than in past, because of the reduced capability to leave the flat for accomplishing other practices with respect to the past, most notably when living in central urban areas); this may contribute to higher energy demand for domestic heating.

The references of the interviewees to other practices such as eating warm meals or taking hot showers for thermal comfort are marginal. The researchers suspect that interviewees may not directly relate these practices with the situated need of warming up the body. The researchers avoided to insist on these elements during the interviews because practices are part of "the routine accomplishment of what people taken to be normal and ordinary practice" [55], to the extent that these actions become invisible to the practitioner.

\subsection{Continuity with Competences and Devices}

Continuity in practice emerges likewise from the analysis of the nexus between the elements of materials and competences. In line with other scholars [47,48,57], the variable comfortable conditions result from a set of actions accomplished by the occupants through a relatively wide range of material elements available to them (e.g., textile layers, thermoregulating devices and building infrastructure), the preference of which is intertwined with the element of competences (e.g., skills and embodied know-how).

Programmable thermostats could facilitate a stress-free preservation of the preferred temperature to be synchronized with the routines of the householders. Nevertheless, some interviewees reported major difficulties in achieving an effect, which is consistent with their intentions when programming this device, predominantly because of ineffective interface and hardly accessible instructions. Such difficulties are reported more frequently by female representatives, thus sustaining gender implications of building retrofit $[76,85]$. Literature confirms that a considerable range of thermostats appear confusing and difficult to use [86-90] even to highly educated testers, with untapped energy saving deriving from optimal programming and use [74,91]. As highlighted by a Municipality technician involved in the definition of the procurement document for this case study, programmable thermostats in new or retrofitted buildings equipped with central heating systems are required to enable at least two sets of temperature to be programmed in a 24-h timescale. He reports that the market offers fairly homogenous, scarcely varied products, especially if analogic (non-digital) less expensive devices are considered to reduce costs and expenditures in public interventions.

In the cases of frustrating experiences for the interviewees with the programmable thermostats, radiator valves become a main means of general thermoregulation, rather than fine tuning. We infer that tenants prefer devices which meet or are aligned with the competences that they were mastering 
in order to achieve thermal comfort conveniently and meaningfully [47]. Similarly, opening and closing window fixtures represent a convenient, accessible ways for adjusting environmental thermal conditions, especially for cooling down promptly. In this respect, material elements switch their role between being infrastructural and working as devices [92]. Double glazing windows-originally intended as infrastructural elements for minimizing heat loss while providing natural light-are actively manipulated to regulate temperature and change air (in addition to the mechanical ventilation); conversely, the programmable thermostat shifts its role into a fixed infrastructural element for those who struggle for setting and adjusting this device.

Even fundamental information on the building infrastructures and instructions for setting devices were not systematically provided to the incoming tenants. Therefore, occupants mostly relied on their understanding and mastered competences for setting and using the thermoregulating devices available to them.

As inferred by Rinkinen and Jalas in their investigation on thermal practices after moving into a new house in Finland [47], "while occupants (as the carriers of practices) encounter elements that are new to them at the time of moving, the trajectories of practitioners and the multiple elements of practices link over-these links can be more or less dormant, activating at the time of moving."

Competences mastered in former experiences and embodied know-how are re-connected in thermal regulation. Working experiences accrued in the construction sector or related field provide opportunities for mastering abilities which came of use when setting the programmable thermostat, declared Paolo; this condition seems to apply also to most of the other interviewees who declared to be able to manage their programmable thermostat successfully, including Ignazio (builder) and Carlo (retired contract furniture manufacturer).

As highlighted by Royston in her extensive account of energy and indoor heating practice [93], know-how is dynamic, responding to changes in life-course, material arrangements and social understanding for instance. In our case study, the competence mastered over time results into an ambivalent nature. On one hand, other tenants benefitted from the embodied know-how of the expert tenants or acquaintances, because the latter either taught how to program the thermostat or accomplished the task on behalf of the less expert tenants. In line with Brown et al. [94], the difficulty to understand the heating system is reported as frustrating or aggravating, prompting occupants to involve technically proficient acquaintances. Making competence available and circulating within the wider local community may provide opportunities for activating social relationships in the recently formed community investigated in this case study.

On the other hand, the mastered competence results into an imbalanced power relation between members of the same household, with tensions for negotiating ideal thermal conditions and temperature that the sole expert householder is capable to set.

\section{Conclusions}

This study discusses the theme of performance gap and occupant behavior in building retrofit, analyzing a case study of a recently retrofitted public housing in Milan inhabited by 500+ tenants. With reference to the energy use in winter, a significant performance gap equal to $80 \%$ is found and occupant dynamics are thus investigated to better outline the practices of indoor heating.

The data and analysis presented support the view that the achievement of thermal comfort is entangled in webs of elements determining the actual use of energy, with multiple elements contributing to the thermal environmental experience and comfort [95]. These include preferences of environmental conditions, rooted habits and shared norms (e.g., hot indoor temperature, wearing light clothes, need for fresh air); the synchronization with daily routines (e.g., working, entertaining); dexterity with devices and convenience in their use (e.g., programmable thermostat, building infrastructures).

Each of these elements could be unpacked in higher level of detail; in this study, the authors intended to bring evidence towards the acknowledgment that routines, ways of doing, understandings of comfort and devices pre-exist to the energy retrofit interventions, and they are reproduced by the 
occupants of the building by adapting the elements available to them in the new situation. Figure 8 summarizes the key insights deriving from of the investigation of the case study. Emphasized are the types of change introduced especially by the retrofit intervention (which may coincide with tenants relocating into a different building and area) in the flux of occupant's life, built on practices for managing thermal comfort, other practices and competences engaged with them.

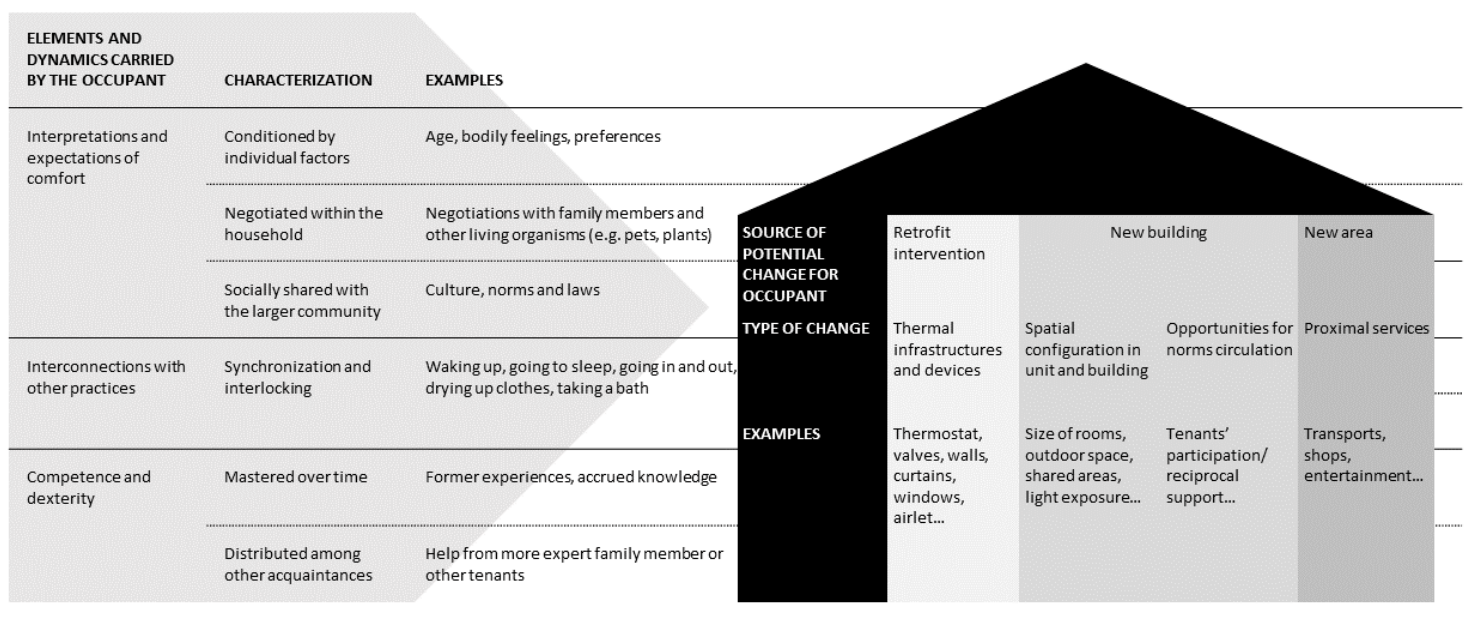

Figure 8. Most relevant insights deriving from of the investigation of the case study. In particular, the scheme emphasizes that building retrofit may introduce change and disruption in the ways people carry on practice and daily routines, if elements (including materials and competences) cannot be reconfigured in continuity with formerly established patterns.

Preferences and ways of doing may derive from rooted customs, constructed over time and established through continuous reproduction. Continuity in practice, i.e., performing routines with similar longitudinal patterns, emerges from the interviews in multiple respects. For instance, the continuity is reflected in limited variations of the way thermal comfort is expected and achieved, namely after relocating in a different country.

Continuity emerges likewise with reference to major disruptions, including the relocation into the new apartment and related urban area. Moving into a less lively area may induce alternative forms in ways of being entertained, with increased time spent at home and energy used for domestic thermal conditioning.

The energy performance gap concept opening this study is to be reframed upon the results presented, especially when behaviors are considered; according to the authors, this part of the gap lies between the expected and actual routinization of dynamics and rules that come along with the retrofit interventions. Or, in other words, between the actual patterns of thermal comfort and the designer's way of thinking of them. As stated by Suchman et al. [96], "individual technologies add value only to the extent they are assembled together into effective configurations". What is potentially effective for designers may not coincide with the situated performance of practices for the occupants of the designed intervention.

We acknowledge that designers of the building, of its thermoregulating infrastructure and devices are asked to meet and abide by norms, regulations and standards. The elements of thermal practices identified are not necessarily tangible, measurable, rational to the extent that they may be translated effectively into occupant's behaviors modeling and retrofit intervention plans; nevertheless, they significantly affect building energy use, more precisely they constitute it.

This suggests that "lower-carbon society supposes and requires significantly new ways of conceptualizing and realizing conditions of comfort" [97]. Building on the insights of this investigation, the authors infer that designing and planning for energy efficient buildings requires a departure from a conventional approach, in which occupants need to adapt to the novel environment produced by the intervention including retrofit. A design approach based on the way people live in, around and outside 
the building may enable the performance of practices with less or minimal energy. Building retrofit intervention constitutes a plausible element of discontinuity and change in more or less routinized practice. Therefore, more analytical understanding of tenants' ways of living may generate more accurate energy assessment during design phase [98]; social practice theory may contribute to provide useful knowledge.

More specifically, the collected data may encourage policy makers and designers engaged in the energy implementation of public housing stock to account for:

- social differentiation of heating practice across diverse segments of population, especially for elderly people or families originating from a different country;

- the communicative effectiveness of the interface of thermoregulating devices-most notably programmable thermostats-to be installed, which is currently missing from the requirement lists in procurement documents;

- systemic integration of local community reciprocal support, namely through the acknowledgement of group of interest and delegation of some tasks by the involved organizations (e.g., the municipality as the owner and managing company), for implemented circulation of information, knowledge and skills;

- diverse practices connected to temperature and heating, such as airing or laundering, for improved environmental design and modeling.

Necessarily the findings of this research refer to a single case study, especially in relation to the limits of this research; most notably, the relatively limited sample of the interviewees; the partial representativeness of the sample with respect to the local community, because of the difficulty of approaching and engaging other tenants; the extensive period of the interviews, due to the difficulty of reaching out people. Therefore, additional studies are needed and encouraged to shed more light and possibly validate the insights generated through this project, most remarkably regarding sociodemographic factors and energy use. Nevertheless, elements for thermal comfort recurred across the interviews and fall into broad categories, which are expectedly recurrent in diverse contexts.

In this respect, the authors intended to verify through this case study how practices could be framed in order to understand change on a wider scale. The case study helps in shedding light on general dynamics rather than in solving a context-specific problem. In fact, the outcomes of the study will inform and possibly raise constructive inputs in plans and policies on one hand, for future energy efficiency and on the other hand on marginality and fragility in public housing, in Milan and possibly also in a wider scale.

Strategies for extending and partly replicating the study presented may be developed through ad hoc guidelines or implementation of existing ones whenever available, which introduce or emphasize the social element in managing heating at home and achieving thermal comfort more broadly. Hence, when it comes to disruptive retrofitting interventions, the authors encourage to complement the energy diagnosis of the building with the diagnosis of the social dimensions and practices before making decisions on design and solutions. Similar instruments will guide through the collection of relevant data presented above (e.g., cultural norms, dexterity with devices, elements of vulnerability) and the generation of strategies for implementing energy effective solutions. The strategies may be based on responses provided by the tenants living in building to be retrofitted, inferred from statistical records of the public housing owner (or manager) or on norms for population cluster allocation (operating in the region of the case study).

Author Contributions: Conceptualization, G.S. and E.M.; methodology, G.S.; investigation, G.S., F.R. and A.S.; data curation and formal analysis G.S. and A.S.; writing-original draft preparation, G.S.; writing-review and editing, G.S., E.M., F.R., A.S., S.E., F.C., L.P.; visualization, G.S., A.S. and S.E.; supervision, L.P.; project administration, E.M. and G.S.; funding acquisition, L.P., A.S., E.M. and G.S. All authors have read and agreed to the published version of the manuscript.

Funding: The EnerPOP project informing this work received funding from Polisocial Award 2017 of Politecnico di Milano. The retrofit of the building and the installation of monitoring equipment was partially funded by the 
European Union's Seventh Framework Program for research, technological development and demonstration under grant agreement No ENER/FP7EN/314632/EU-GUGLE. The retrofit of the building was also partially funded by Italy's national subsidy scheme Conto Termico.

Conflicts of Interest: The authors declare no conflicts of interest. The funders had no role in the design of the study; in the collection, analyses or interpretation of data; in the writing of the manuscript or in the decision to publish the results.

\section{References}

1. Lucon, O.; Ürge-Vorsatz, D.; Zain Ahmed, A.; Akbari, H.; Bertoldi, P.; Cabeza, L.F.; Eyre, N.; Gadgil, A.D.; Harvey, L.D.; Jiang, Y.; et al. Buildings. In Climate Change 2014: Mitigation of Climate Change; Contribution of Working Group III to the Fifth Assessment Report of the Intergovernmental Panel on Climate, Change; Edenhofer, O.R., Pichs-Madruga, Y., Sokona, E., Farahani, S., Kadner, K., Seyboth, A., Adler, I., Baum, S., Brunner, P., Eickemeier, B., et al., Eds.; Cambridge University Press: Cambridge, UK; New York, NY, USA, 2014; pp. 671-738.

2. Ma, Z.; Cooper, P.; Daly, D.; Ledo, L. Existing building retrofits: Methodology and state-of-the-art. Energy Build. 2012, 55, 889-902. [CrossRef]

3. Melgar, S.G.; Martínez Bohórquez, M.Á.; Andújar Márquez, J.M. uhuMEBr: Energy refurbishment of existing buildings in subtropical climates to become minimum energy buildings. Energies 2020, 13, 1204. [CrossRef]

4. The European Parliament; Council of the European Union. Directive 2012/27/EU of the European Parliament and of the Council of 25 October 2012 on Energy Efficiency Amending Directives 2009/125/EC and 2010/30/EU and Repealing Directives 2004/8/EC and 2006/32/EC. Off. J. Eur. Union 2012, 315, 1-56.

5. Paoletti, G.; Pascuas, R.P.; Pernetti, R.; Lollini, R. Nearly Zero Energy Buildings: An overview of the main construction features across Europe. Buildings 2017, 7, 43. [CrossRef]

6. Santangelo, A.; Tondelli, S. Occupant behaviour and building renovation of the social housing stock: Current and future challenges. Energy Build. 2017, 145, 276-283.

7. Elsharkawy, H.; Rutherford, P. Retrofitting social housing in the UK: Home energy use and performance in a pre-Community Energy Saving Programme (CESP). Energy Build. 2015, 88, 25-33.

8. Monteiro, C.S.; Causone, F.; Cunha, S.; Pina, A.; Erba, S. Addressing the challenges of public housing retrofits. Energy Procedia 2017, 134, 442-451. [CrossRef]

9. International Energy Agency; United Nations Environment Programme. 2018 Global Status Report: Towards a Zero-Emission, Efficient And Resilient Buildings And Construction Sector; International Energy Agency: Paris, France; United Nations: New York, NY, USA, 2018.

10. Italian National Energy Efficiency Agency. Italy's Energy Efficiency Annual Report; Italian National Energy Efficiency Agency: Rome, Italy, 2016; 29p.

11. Palm, J.; Reindl, K. Understanding energy efficiency in Swedish residential building renovation: A practice theory approach. Energy Res. Soc. Sci. 2016, 11, 247-255. [CrossRef]

12. UK Department for Business, Energy \& Industrial Strategy. Energy Consumption in the UK: Overall Energy Consumption in the UK Since 1970; UK Department for Business, Energy \& Industrial Strategy: London, UK, 2018.

13. European Commission. Communication From the Commission to the European Parliament, the Council, the European Economic and Social Committee and the Committee of the Regions: A Roadmap for Moving to a Competitive Low Carbon Economy in 2050; European Commission: Brussels, Belgium, 2011.

14. van den Brom, P.; Meijer, A.; Visscher, H. Performance gaps in energy consumption: Household groups and building characteristics. Build. Res. Inf. 2018, 46, 54-70. [CrossRef]

15. Sunikka-Blank, M.; Galvin, R. Introducing the prebound effect: The gap between performance and actual energy consumption. Build. Res. Inf. 2012, 40, 260-273. [CrossRef]

16. De Wilde, P. The gap between predicted and measured energy performance of buildings: A framework for investigation. Autom. Constr. 2014, 41, 40-49. [CrossRef]

17. Galvin, R. Making the "rebound effect" more useful for performance evaluation of thermal retrofits of existing homes: Defining the "energy savings deficit" and the "energy performance gap". Energy Build. 2014, 69, 515-524. [CrossRef]

18. Galvin, R. The Rebound Effect in Home Heating: A Guide for Policymakers and Practitioners; Routledge: Oxon, UK, 2015; ISBN 9781138788350. 
19. Zou, P.X.W.; Xu, X.; Sanjayan, J.; Wang, J. Review of 10 years research on building energy performance gap: Life-cycle and stakeholder perspectives. Energy Build. 2018, 178, 165-181. [CrossRef]

20. Fabrizio, E.; Monetti, V. Methodologies and advancements in the calibration of building energy models. Energies 2015, 8, 2548-2574. [CrossRef]

21. Qi, Y.; Qian, Q.; Meijer, F.; Visscher, H. Causes of Quality Failures in Building Energy Renovation Projects of Northern China: A Review and Empirical Study. Energies 2020, 13, 2442. [CrossRef]

22. Shi, X.; Si, B.; Zhao, J.; Tian, Z.; Wang, C.; Jin, X.; Zhou, X. Magnitude, causes, and solutions of the performance gap of buildings: A review. Sustainability 2019, 11, 1-21.

23. Janda, K.B. Buildings don't use energy: People do. Archit. Sci. Rev. 2011, 54, 15-22. [CrossRef]

24. Gill, Z.M.; Tierney, M.J.; Pegg, I.M.; Allan, N. Low-energy dwellings: The contribution of behaviours to actual performance. Build. Res. Inf. 2010, 38, 491-508. [CrossRef]

25. Haas, R.; Auer, H.; Biermayr, P. The impact of consumer behavior on residential energy demand for space heating. Energy Build. 1998, 27, 195-205. [CrossRef]

26. Sun, K.; Hong, T. A framework for quantifying the impact of occupant behavior on energy savings of energy conservation measures. Energy Build. 2017, 146, 383-396. [CrossRef]

27. Guerra-Santin, O.; Boess, S.; Konstantinou, T.; Romero Herrera, N.; Klein, T.; Silvester, S. Designing for residents: Building monitoring and co-creation in social housing renovation in the Netherlands. Energy Res. Soc. Sci. 2017, 32, 164-179. [CrossRef]

28. Deme Belafi, Z.; Hong, T.; Reith, A. A critical review on questionnaire surveys in the field of energy-related occupant behaviour. Energy Effic. 2018, 11, 2157-2177. [CrossRef]

29. Karatas, A.; Stoiko, A.; Menassa, C.C. Framework for selecting occupancy-focused energy interventions in buildings. Build. Res. Inf. 2016, 44, 535-551. [CrossRef]

30. Huebner, G.M.; McMichael, M.; Shipworth, D.; Shipworth, M.; Durand-Daubin, M.; Summerfield, A. The reality of English living rooms-A comparison of internal temperatures against common model assumptions. Energy Build. 2013, 66, 688-696. [CrossRef]

31. Causone, F.; Carlucci, S.; Ferrando, M.; Marchenko, A.; Erba, S. A data-driven procedure to model occupancy and occupant-related electric load profiles in residential buildings for energy simulation. Energy Build. 2019, 202, 109342. [CrossRef]

32. Patel, H.; Green, S.D. Beyond the performance gap: Reclaiming building appraisal through archival research. Build. Res. Inf. 2019, 1-16. [CrossRef]

33. Shove, E. Beyond the ABC: Climate change policy and theories of social change. Environ. Plan. A 2010, 42, 1273-1285. [CrossRef]

34. Ambrose, A.; Goodchild, B.; O'Flaherty, F. Understanding the user in low energy housing: A comparison of positivist and phenomenological approaches. Energy Res. Soc. Sci. 2017, 34, 163-171. [CrossRef]

35. Stazi, F.; Naspi, F.; D'Orazio, M. A literature review on driving factors and contextual events influencing occupants' behaviours in buildings. Build. Environ. 2017, 118, 40-66. [CrossRef]

36. Hargreaves, T. Practice-ing behaviour change: Applying social practice theory to pro-environmental behaviour change. J. Consum. Cult. 2011, 11, 79-99. [CrossRef]

37. Kuijer, L.; Bakker, C. Of chalk and cheese: Behaviour change and practice theory in sustainable design. Int. J. Sustain. Eng. 2015, 8, 219-230. [CrossRef]

38. Coleman, S.; Touchie, M.F.; Robinson, J.B.; Peters, T. Rethinking performance gaps: A regenerative sustainability approach to built environment performance assessment. Sustainability 2018, 10, 4826. [CrossRef]

39. Dunlop, T. Mind the gap: A social sciences review of energy efficiency. Energy Res. Soc. Sci. 2019, 56, 101216. [CrossRef]

40. Moezzi, M.; Janda, K.B. From "if only" to "social potential" in schemes to reduce building energy use. Energy Res. Soc. Sci. 2014, 1, 30-40. [CrossRef]

41. Tweed, C. Socio-technical issues in dwelling retrofit. Build. Res. Inf. 2013, 41, 551-562. [CrossRef]

42. Maller, C.; Horne, R.; Dalton, T. Green Renovations: Intersections of Daily Routines, Housing Aspirations and Narratives of Environmental Sustainability. Hous. Theory Soc. 2012, 29, 255-275. [CrossRef]

43. Chiu, L.F.; Lowe, R.; Raslan, R.; Altamirano-Medina, H.; Wingfield, J. A socio-technical approach to post-occupancy evaluation: Interactive adaptability in domestic retrofit. Build. Res. Inf. 2014, 42, 574-590. [CrossRef] 
44. Hand, M.; Shove, E.; Southerton, D. Home extensions in the United Kingdom: Space, time, and practice. Environ. Plan. D Soc. Space 2007, 25, 668-681. [CrossRef]

45. Ortiz, M.A.; Kurvers, S.R.; Bluyssen, P.M. A review of comfort, health, and energy use: Understanding daily energy use and wellbeing for the development of a new approach to study comfort. Energy Build. 2017, 152, 323-335. [CrossRef]

46. Chappells, H.; Shove, E. Debating the future of comfort: Environmental sustainability, energy consumption and the indoor environment. Build. Res. Inf. 2005, 33, 32-40. [CrossRef]

47. Rinkinen, J.; Jalas, M. Moving home: Houses, new occupants and the formation of heating practices. Build. Res. Inf. 2017, 45, 293-302. [CrossRef]

48. Shove, E. Comfort, Cleanliness and Convenience: The Social Organization of Normality; Berg Publishers: Oxford, UK, 2003.

49. Shove, E.; Walker, G. What Is Energy For? Social Practice and Energy Demand. Theory Cult. Soc. 2014, 31, 41-58. [CrossRef]

50. Schatzki, T.R. Introduction: Practice theory. In The Practice Turn in Contemporary Theory; Schatzki, T.R., Knorr Cetina, K., von Savigny, E., Eds.; Routledge: London, UK; New York, NY, USA, 2001; pp. 1-14.

51. Warde, A. Consumption and Theories of Practice. J. Consum. Cult. 2005, 5, 131-153. [CrossRef]

52. Shove, E.; Pantzar, M.; Watson, M. The Dynamics of Social Practice: Everyday Life and how it Changes; SAGE: London, UK, 2012.

53. Reckwitz, A. Toward a Theory of Social Practices. Eur. J. Soc. Theory 2002, 5, 243-263. [CrossRef]

54. Spaargaren, G. Theories of practices: Agency, technology, and culture. Exploring the relevance of practice theories for the governance of sustainable consumption practices in the new world-order. Glob. Environ. Chang. 2011, 21, 813-822. [CrossRef]

55. Shove, E. Efficiency and Consumption. Energy Environ. 2004, 15, 1053-1065. [CrossRef]

56. Shove, E.; Watson, M.; Hand, M.; Ingram, J. The Design of Everyday Life; Berg Publishers: Oxford, UK, 2007.

57. Gram-Hanssen, K. Understanding change and continuity in residential energy consumption. J. Consum. Cult. 2011, 11, 61-78. [CrossRef]

58. Madsen, L.V. Materialities shape practices and notions of comfort in everyday life. Build. Res. Inf. 2018, 46, 71-82. [CrossRef]

59. Madsen, L.V.; Gram-Hanssen, K. Understanding comfort and senses in social practice theory: Insights from a Danish field study. Energy Res. Soc. Sci. 2017, 29, 86-94. [CrossRef]

60. Galvin, R. Impediments to energy-efficient ventilation of German dwellings: A case study in Aachen. Energy Build. 2013, 56, 32-40. [CrossRef]

61. DellaValle, N.; Bisello, A.; Balest, J. In search of behavioural and social levers for effective social housing retrofit programs. Energy Build. 2018, 172, 517-524. [CrossRef]

62. Mela, H.; Peltomaa, J.; Salo, M.; Mäkinen, K.; Hildén, M. Framing smart meter feedback in relation to practice theory. Sustainability 2018, 10, 3553. [CrossRef]

63. Gram-Hanssen, K. Residential heat comfort practices: Understanding users. Build. Res. Inf. 2010, 38, 175-186. [CrossRef]

64. Judson, E.P.; Maller, C. Housing renovations and energy efficiency: Insights from homeowners practices. Build. Res. Inf. 2014, 42, 501-511. [CrossRef]

65. Sangalli, A.; Pagliano, L.; Causone, F.; Salvia, G.; Morello, E. Energy efficiency and occupants' behavior: Analysis of a public housing case study. In Proceedings of the AICARR 51st International Conference "The Human Dimension of Building Energy Performance", Venice, Italy, 20-22 February 2019; pp. 643-656.

66. Sangalli, A.; Pagliano, L.; Causone, F.; Salvia, G.; Morello, E.; Erba, S. Behavioural change effects on energy use in public housing: A case study. In Sustainability in Energy and Buildings Proceedings of SEB 2019; Littlewood, J., Howlett, R.J., Capozzoli, A., Jain, L., Eds.; Springer: Singapore, 2020.

67. Presidente della Repubblica. Decreto del Presidente della Repubblica 26 agosto 1993, n. 412. Regolamento recante norme per la progettazione, l'installazione, l'esercizio e la manutenzione degli impianti termici degli edifici ai fini del contenimento dei consumi di energia. Available online: https:/www.normattiva.it/uri-res/ N2Ls?urn:nir:stato:legge:1993;412 \{\}art2!vig= (accessed on 1 June 2020).

68. EU-GUGLE. Milano. Available online: http://eu-gugle.eu/pilot-cities/milano (accessed on 1 June 2020).

69. Robson, C. Real World Research: A Resource for Social Scientists and Practitioner-Researchers, 2nd ed.; Blackwell: Oxford, UK, 2002; Volume 2, ISBN 0631213058. 
70. Hitchings, R. People can talk about their practices. Area 2012, 44, 61-67. [CrossRef]

71. Hitchings, R.; Latham, A. Qualitative methods I: On current conventions in interview research. Prog. Hum. Geogr. 2019, 44, 389-398. [CrossRef]

72. NVivo. Available online: https://www.qsrinternational.com/nvivo-qualitative-data-analysis-software/home (accessed on 27 June 2020).

73. Strengers, Y.; Nicholls, L.; Maller, C. Curious energy consumers: Humans and nonhumans in assemblages of household practice. J. Consum. Cult. 2016, 16, 761-780. [CrossRef]

74. Meier, A.; Aragon, C.; Peffer, T.; Pritoni, M. Thermostat Interface and Usability: A Survey; US Department of Energy: Washington, DC, USA, 2010.

75. Kane, T.; Firth, S.K.; Lomas, K.J. How are UK homes heated? A city-wide, socio-technical survey and implications for energy modelling. Energy Build. 2015, 86, 817-832. [CrossRef]

76. Tjørring, L.; Gausset, Q. Drivers for retrofit: A sociocultural approach to houses and inhabitants. Build. Res. Inf. 2019, 47, 394-403. [CrossRef]

77. Nicholls, L.; Strengers, Y. Peak demand and the "family peak" period in Australia: Understanding practice (in)flexibility in households with children. Energy Res. Soc. Sci. 2015, 9, 116-124. [CrossRef]

78. Salvia, G.; Rotondo, F.; Morello, E.; Sangalli, A.; Pagliano, L.; Causone, F. Sustainability designed with(out) people? Understanding for what energy is (over-) used by tenants in an energy efficient public housing in Milan. In Proceedings of the 3rd LeNS World Distributed Conference "Designing Sustainability For All"; Ambrosio, M., Vezzoli, C., Eds.; POLI.design: Milan, Italy, 2019; pp. 1027-1031.

79. Darby, S. Energy feedback in buildings: Improving the infrastructure for demand reduction. Build. Res. Inf. 2008, 36, 499-508. [CrossRef]

80. Strengers, Y.; Maller, C. Integrating health, housing and energy policies: Social practices of cooling. Build. Res. Inf. 2011, 39, 154-168. [CrossRef]

81. Eon, C.; Breadsell, J.K.; Morrison, G.M.; Byrne, J. The home as a system of practice and its implications for energy and water metabolism. Sustain. Prod. Consum. 2018, 13, 48-59. [CrossRef]

82. Breadsell, J.; Eon, C.; Morrison, G.; Kashima, Y. Interlocking practices and their influence in the home. Environ. Plan. B Urban. Anal. City Sci. 2019, 46, 1405-1421. [CrossRef]

83. Hauge, B. The air from outside: Getting to know the world through air practices. J. Mater. Cult. 2013, 18, 171-187. [CrossRef]

84. Lindén, A.L.; Carlsson-Kanyama, A.; Eriksson, B. Efficient and inefficient aspects of residential energy behaviour: What are the policy instruments for change? Energy Policy 2006, 34, 1918-1927. [CrossRef]

85. Sunikka-Blank, M.; Galvin, R.; Behar, C. Harnessing social class, taste and gender for more effective policies. Build. Res. Inf. 2018, 46, 114-126. [CrossRef]

86. Shipworth, M.; Firth, S.K.; Gentry, M.I.; Wright, A.J.; Shipworth, D.T.; Lomas, K.J. Central heating thermostat settings and timing: Building demographics. Build. Res. Inf. 2010, 38, 50-69. [CrossRef]

87. Wade, F.; Shipworth, M.; Hitchings, R. How installers select and explain domestic heating controls. Build. Res. Inf. 2017, 45, 371-383. [CrossRef]

88. Combe, N.; Harrison, D.; Craig, S.; Young, M.S. An investigation into usability and exclusivity issues of digital programmable thermostats. J. Eng. Des. 2012, 23, 401-417. [CrossRef]

89. Munton, A.G.; Wright, A.J.; Mallaburn, P.S.; Boait, P.J. How Heating Controls Affect Domestic Energy Demand: A Rapid Evidence Assessment. A Report to the Department of Energy and Climate Change; DECC: London, UK, 2014.

90. Meier, A.; Aragon, C.; Hurwitz, B.; Mujumda, D.; Peffer, T.; Perry, D. How People Actually Use Thermostats; ACEEE Summer Study on Energy Efficiency in Buildings: Pacific Grove, CA, USA, 2012; pp. 193-206.

91. Peffer, T.; Perry, D.; Pritoni, M.; Aragon, C.; Meier, A. Facilitating energy savings with programmable thermostats: Evaluation and guidelines for the thermostat user interface. Ergonomics 2013, 56, 463-479. [PubMed]

92. Shove, E. Matters of practice. In The Nexus of Practices: Connections, Constellations, Practitioners; Taylor \& Francis: Milton Park, UK, 2016; ISBN 9781138675155.

93. Royston, S. Dragon-breath and snow-melt: Know-how, experience and heat flows in the home. Energy Res. Soc. Sci. 2014, 2, 148-158. [CrossRef]

94. Brown, P.; Swan, W.; Chahal, S. Retrofitting social housing: Reflections by tenants on adopting and living with retrofit technology. Energy Effic. 2014, 7, 641-653. [CrossRef]

95. Heschong, L. Thermal Delight in Architecture; MIT Press: Cambridge, MA, USA, 1979; ISBN 026258039-X. 
96. Suchman, L.; Blomberg, J.; Orr, J.E.; Trigg, R. Reconstructing Technologies as Social Practice. Am. Behav. Sci. 1999, 43, 392-408.

97. Shove, E.; Chappells, H.; Lutzenhiser, L.; Hackett, B.; Shove, E.; Chappells, H.; Lutzenhiser, L.; Hackett, B. Comfort in a lower carbon society. Build. Res. Inf. 2008, 36, 307-311. [CrossRef]

98. Becchio, C.; Bello, C.; Corgnati, S.P.; Ingaramo, L. Influence of Occupant Behaviour Lifestyle on an Italian Social Housing. Energy Procedia 2016, 101, 1034-1041. [CrossRef]

(C) 2020 by the authors. Licensee MDPI, Basel, Switzerland. This article is an open access article distributed under the terms and conditions of the Creative Commons Attribution (CC BY) license (http://creativecommons.org/licenses/by/4.0/). 